\title{
La biblioteca, espacio de cultura y participación (J. A. Gómez y Pedro Quílez, coord.)
}

\author{
Por Carme Fenoll-Clarabuch
}

Fenoll-Clarabuch, Carme. "La biblioteca, espacio de cultura y participación (Gómez-Hernández, José-Antonio; Quílez-Simón, Pedro)". Reseña de libro. En: El profesional de la información, 2008, marzo-abril, v. 17, n. 2, pp. 247-248.

DOI: 10.3145/epi.2008.mar.19

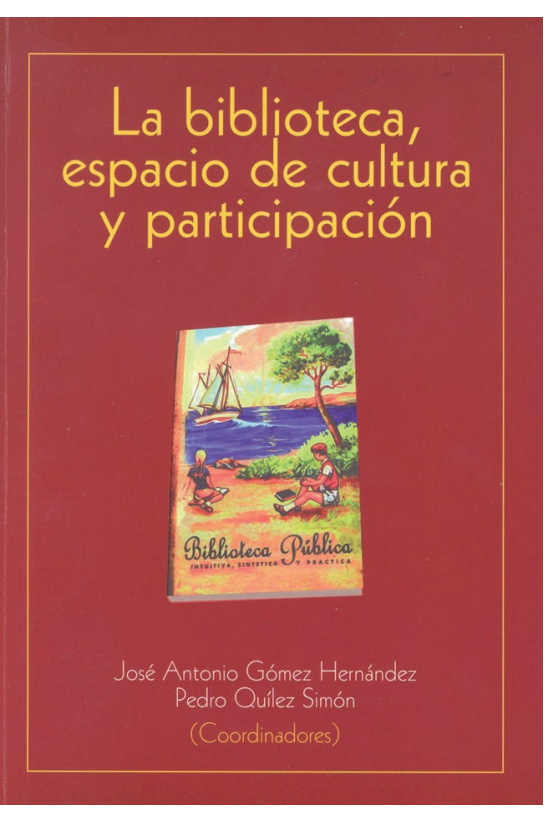

LOS ASISTENTES AL VIII CONGRESO DE ANABAD "Memoria y tecnología" celebrado en Madrid los días 13-15 de febrero de 2008, tuvimos el privilegio de conocer este libro primicia, obra conjunta de 9 autores coordinados por José-Antonio Gómez-Hernández y Pedro Quílez-Simón.

Responsables en buena medida del auge e impulso de las bibliotecas públicas de la Comunidad murciana, Gómez -profesor de Biblioteconomía en la Universidad de Murcia- y Quílez -responsable de cultura en la Biblioteca Regional de Murcia- complementan a la perfección sus vertientes profesionales y conocimientos prácticos y nos proponen una obra conjunta y complementaria a sus interesantes aportaciones sobre el tema de la dinamización en las bibliotecas.
Dos partes de cuatro capítulos cada una, forman este libro de formato fácil y claro. En la primera, titulada "Gestión cultural, planificación y márketing en bibliotecas públicas. Aspectos teóricos", se reflexiona sobre planificación en gestión cultural en bibliotecas con el trabajo de Isabel Blanco Pardo, fruto de su larga experiencia como directora del Servicio Municipal de Bibliotecas de A Coruña. Una actualizada bibliografía completa el capítulo.

Continúa el libro con un texto que permite comprender los fundamentos del marketing y la promoción de las actividades culturales y sus tendencias, escrito por los profesores de Biblioteconomía de la Universidad de Extremadura Margarita Pérez-Pulido y JoséLuis Herrera-Morillas. Tras esos dos capítulos, el siguiente trata sobre la promoción cultural y la lectura en el contexto de internet y las redes sociales, y está escrito per José-María Barandiarán, consultor experto en el mundo editorial y del libro. El autor nos introduce de forma sugerente y divertida a "Lectura y red: nuevas estrategias de promoción del libro. ¿Qué lío! ¿No?”. Se da un repaso a los términos más frecuentes, habla en primera persona -desde su experiencia en el blog Opinionconvalor ${ }^{1}$ - de la relación y los problemas comunes de las bibliotecas con otros elementos como el sector editorial o las librerías, y explica con numerosas ilustracio-

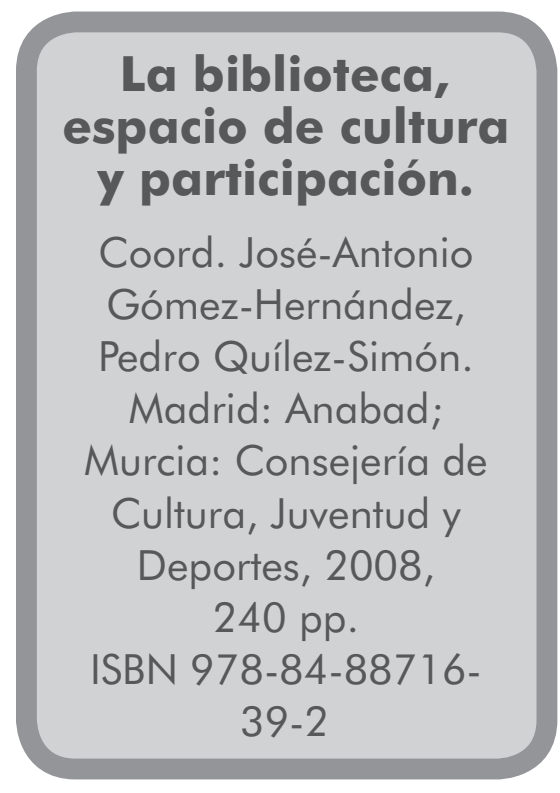

nes en cuadricromía y gráficos, las posibilidades y dificultades de las herramientas tecnológicas de participación en internet, como blogs, wikis o marcadores sociales.

$\mathrm{Y}$ el último texto de esta parte más teórica describe las competencias básicas y los conocimientos que deben tener los gestores y programadores culturales de las bibliotecas para la ejecución de su trabajo. Recogiendo su experiencia en el tema, Pedro Quílez-Simón, vincula las características del trabajo con las herramientas tecnológicas de diseño y programación existentes, los conocimientos conceptuales y técnicos para seleccionar actividades, organizar exposiciones, relacionarse con distintos grupos sociales y culturales, etc. Destaca en este capítulo el desglose muy práctico de habilidades 
y conocimientos para el gestor de actividades. Un ejemplo lo encontramos en una de las citas que reproduce las partes esenciales de un artículo de Mercè Castells ${ }^{2}$.

\section{Y una segunda parte más práctica}

La segunda parte del libro comienza con un texto de 37 páginas titulado "La promoción cultural y educativa desde la biblioteca en el ámbito local: La oreja verde" en el que el bibliotecario Cristóbal Guerrero describe la experiencia en primera línia de 25 años de la Biblioteca de Camas (Sevilla) en una función de inclusión educativa y cultural, a partir de la investigación-acción, la escucha activa de las necesidades locales, la interrelación con la comunidad, y la experiencia, que han llevado a esta biblioteca a ser un motor social de esta ciudad sevillana. Numerosas fotografías complementan un texto que desprende humanidad y estima para una profesión que va mucho más allá de ser la intermediaria entre los libros y unos clientes.

Otra buena práctica descrita es la que recoge el siguiente capítulo, "La biblioteca: un elemento que impulsa y cohesiona los centros culturales", de Villar ArellanoYanguas, de la Biblioteca Civican (Fundación Caja Navarra). En él se explica la función de la biblio- teca como dinamizadora del conjunto del centro cultural donde se encuentra, interrelacionando las actividades, las propuestas, guías y clubes de lectura y los intereses coincidentes del conjunto cultural del que forma parte. El capítulo concluye con estas palabras: "Insertar una biblioteca como núcleo de un centro cultural no es un capricho estético, es construir un mirador, dar perspectiva a los usuarios, vincular su participación con el entorno, complejo y abierto, de la cultura lectora".

El capítulo titulado "Biblioteca e inclusión social y cultural: ¿Posibilidad o necesidad?" contiene las reflexiones de la profesora mexicana Judith Licea-de-Arenas, de la Universidad Nacional Autónoma de México, escritas en colaboración con José A. Gómez, en el que destacan las necesidades de atención a los sectores excluidos o desfavorecidos en las bibliotecas y consideran la previa inclusión social y personal como condición para la inclusión cultural.

Finalmente, el libro se cierra con un capítulo en el que los profesores Herrera-Morillas y PérezPulido describen extensamente los principales medios, ejemplos y experiencias de márketing de las actividades culturales realizadas en España, aunque también resaltan algunos buenos ejemplos norte- americanos. Es por tanto el complemento de todas las reflexiones anteriores.

Sobresalen en todo el libro la actualidad de sus numerosos ejemplos y de su amplia bibliografía.

Los asistentes a las Jornadas con el título homónimo que se realizaron en octubre 2007 en la Biblioteca Regional de Murcia, tuvieron la posibilidad de escuchar y discutir algunas de las reflexiones expuestas y experiencias tratadas ahora en esta obra.

Es de suponer que estos temas serán todavía material de debate en muchas futuras jornadas y congresos de nuestra profesión. Una lectura como la de este libro, amena y de estructura clara, nos facilitará el camino para entender las tendencias en las propuestas culturales que realizan las bibliotecas públicas.

\section{Notas}

1. http://opinionconvalor.nireblog.com/

2. http://www.publidirecta.com/publicidad/publici dad_notasprensa.php

Carme Fenoll-Clarabuch es directora de la Biblioteca de Palafrugell (Girona) y miembro de la Junta Directiva del Col-legi Oficial de Bibliotecaris-Documentalistes de Catalunya (Cobdc). carme.fenoll@cobdc.org

\section{Te damos los ingredientes...}

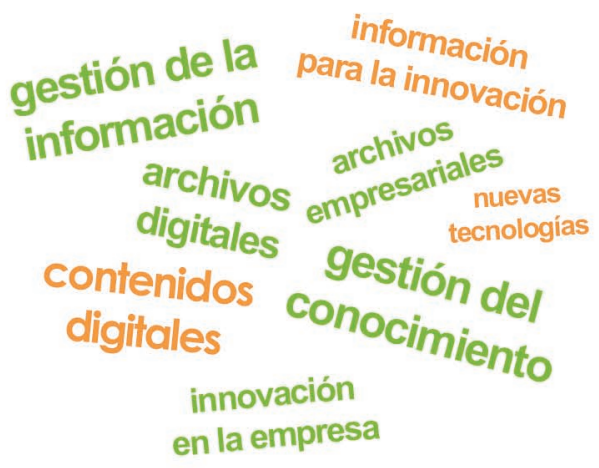

